\title{
The Antitumor Activity and Mechanism of a Natural Diterpenoid From Casearia graveolens
}

\section{OPEN ACCESS}

Edited by:

Peng Qu,

National Institutes of Health $(\mathrm{N} / \mathrm{H})$,

United States

Reviewed by:

Mingxiao Feng,

Johns Hopkins University,

United States

Likui Feng,

The Rockefeller University,

United States

Lin Jiang,

University of Cincinnati,

United States

${ }^{*}$ Correspondence:

Jing $X u$

xujing611@nankai.edu.cn

Yuanqiang Guo

victgyq@nankai.edu.cn

Specialty section:

This article was submitted to Pharmacology of Anti-Cancer Drugs,

a section of the journa

Frontiers in Oncology

Received: 30 March 2021 Accepted: 08 June 2021

Published: 25 June 2021

Citation:

Li Y, Ma J, Song Z, Zhao Y,

Zhang H, Li Y, X U J and

Guo $Y$ (2021) The Antitumor

Activity and Mechanism

of a Natural Diterpenoid From

Casearia graveolens.

Front. Oncol. 11:688195.

doi: 10.3389/fonc.2021.688195

\author{
Ying Li, Jun Ma, Ziteng Song, Yinan Zhao, Han Zhang, Yeling Li, Jing $X u^{*}$ \\ and Yuanqiang Guo* \\ State Key Laboratory of Medicinal Chemistry Biology, College of Pharmacy, Tianjin Key Laboratory of Molecular Drug \\ Research, and Drug Discovery Center for Infectious Disease, Nankai University, Tianjin, China
}

Casearlucin A, a diterpenoid obtained from Casearia graveolens, has been reported to possess strong cytotoxic activity. However, the in vivo anti-tumor effects and the action mechanism of casearlucin A remain poorly understood. Our study revealed that casearlucin A arrested cell cycle at G0/G1 stage and induced cell apoptosis in cell level. Additionally, casearlucin A inhibited HepG2 cell migration via regulating a few of metastasis-related proteins. Furthermore, it inhibited tumor angiogenesis in zebrafish in vivo. More importantly, casearlucin A significantly inhibited cell proliferation and migration in an in vivo zebrafish xenograft model. Collectively, these results are valuable for the further development and application of casearlucin A as an anticancer agent.

Keywords: cytotoxic activity, zebrafish xenograft model, apoptosis, cell cycle, FAK-MMPs, antiangiogenesis inhibitors

\section{INTRODUCTION}

Cancer is the leading cause of death in the world, and the incidence rate is high in many Asian countries including China $(1,2)$. Nowadays, the most common ways to treat cancer are the combination of chemotherapy, radiation therapy, and surgical interventions. However, there are still many problems in current clinical treatment, such as side effects and drug resistances, which urges researchers to develop new treatment strategies or find alternative treatments (3). As we all know, medicinal plants are a promising source for developing new pharmaceuticals, and many wellknown drugs approved by FDA, such as paclitaxel, camptothecin, and artemisinin, have been derived from natural products or their derivatives (4). In the development of new drugs, the main role of natural products is to provide lead compounds, or provide clues for the discovery of lead compounds.

The genus Casearia Jacq. belonging to the family Flacourtiaceae, consists of about 160 species, which distributed widely in tropical Africa, Asia, northwest Australia, and South America. Recent phytochemical studies have revealed the presence of abundant diterpenoids, particularly clerdoane 


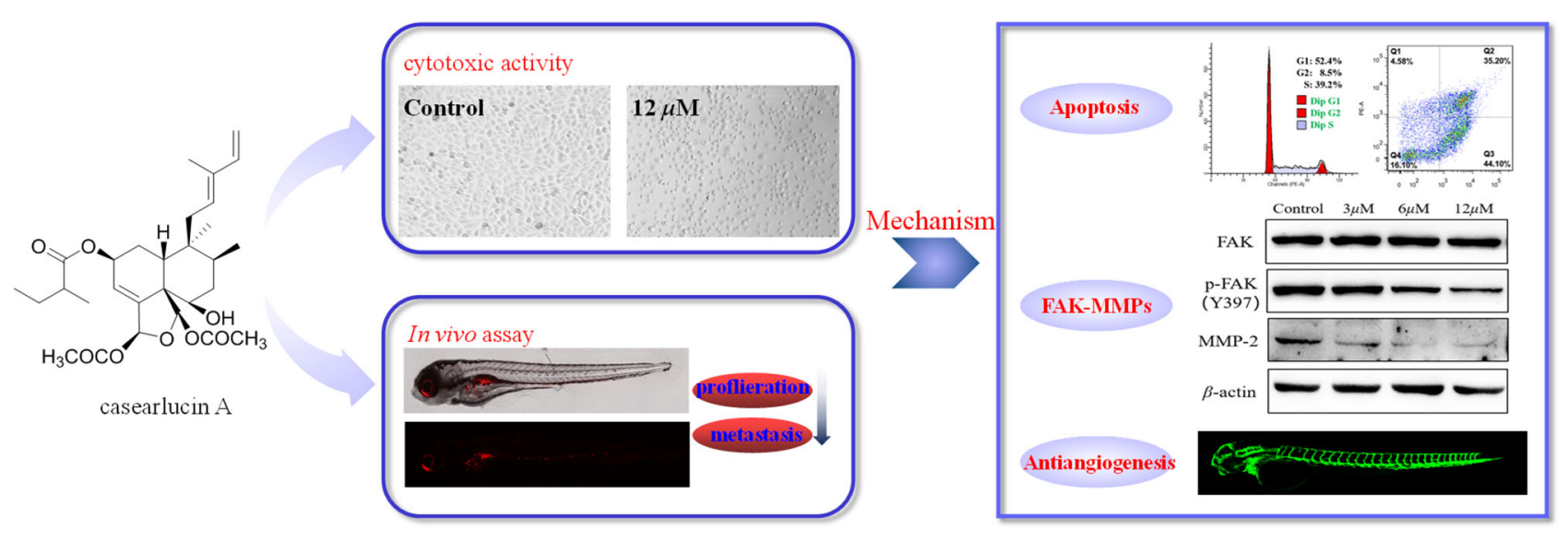

GRAPHICAL ABSTRACT

diterpenoids, in Casearia plants, which showed extensive biological activities, including antimalarial, antimicrobial, antifungal, and cytotoxic activities (5-13). The plant Casearia graveolens evoked our interest, a phytochemical examination aiming to acquire biologically active compounds was thus carried out by our research group. In the previous chemical investigation conducted by our group, nine new clerodane diterpenoids (graveospenes $\mathrm{A}-\mathrm{I}$ ) and three known clerodane diterpenoids (casearlucin A, casearlucin F, and bucidarasin C) was obtained. A biological evaluation of the new compounds was performed, and graveospenes A was found to be cytotoxic (14). Therefore, three known compounds with similar structure to graveospenes A were screened for cytotoxic activity. The results revealed that all of the three compounds were cytotoxic against HepG2, A549, and Hela cell lines, and casearlucin A was the most active. According to the previous literature, there have been no reports on the mechanism of casearlucin A, especially the antitumor effects in vivo. The further research on casearlucin A with remarkable cytotoxicity may be potentially useful for the development of casearlucin A as an anticancer agent.

Casearlucin A with prominent cytotoxic activity attracted our interest, and there is no report on its action mechanism. So, this study aims to investigate the anti-tumor effects in vivo using a zebrafish tumor xenograft, and the anti-tumor mechanism, all of which are important and valuable for the further development and application of casearlucin $\mathrm{A}$ as an anticancer agent.

\section{MATERIALS AND METHODS}

\section{Materials and Cell Culture}

Dulbecco's modified Eagle's medium (DMEM), Fetal bovine serum (FBS, BI, Israel) were purchased from LABBIOTECH Co. Ltd. (Shandong, China). MTT and dimethyl sulfoxide (DMSO) were purchased from Solarbio (Beijing, China). Celltracker CM-DiI was obtained from Yeasen Biotechnology Co. Ltd (Shanghai, China). Annexin V-FITC Apoptosis
Detection Kit, Cell Cycle and Apoptosis Kit, BCA protein assay kit were provided by Beyotime Biotechnology Co. Ltd (Shanghai, China). Rabbit monoclonal antibodies to Bax, Bcl-2, FAK, p-FAK (phospho Y397), MMP-2, $\beta$-actin were all purchased from Cell Signaling Technology (Danvers, MA, USA).

The three cancer cell lines (HepG2, Hela and A549 cells) were obtained from Shanghai Institutes for Biological Sciences, Chinese Academy of Sciences (Shanghai, China). The cells were cultured in DMEM containing 10\% (v/v) fetal bovine serum and $100 \mathrm{U} / \mathrm{mL}$ penicillin/streptomycin under a watersaturated atmosphere of $95 \%$ air and $5 \% \mathrm{CO}_{2}$.

\section{Cytotoxic Activity Assay}

The cytotoxic activities were evaluated using MTT assay (15). Briefly, after reaching approximate $80 \%$ confluence, the cells were harvested and seeded in 96 -well plates $\left(1 \times 10^{4}\right.$ cells/well $)$ and allowed to adhere for $24 \mathrm{~h}$ at $37^{\circ} \mathrm{C}$. Then, the cells were treated with the test samples dissolved in DMSO at different concentrations, including the positive. Etoposide was used as a positive control. After continuous incubation for $48 \mathrm{~h}, 20 \mu \mathrm{L}$ MTT solution ( $5 \mathrm{mg} / \mathrm{mL}$ ) was added in each well for $4 \mathrm{~h}$ incubation. Then, the medium was replaced with $150 \mu \mathrm{L}$ DMSO and the absorbance was measured at $492 \mathrm{~nm}$ using microplate reader (Thermo Fisher Scientific Inc. America). The experiments were performed in triplicate, and the $\mathrm{IC}_{50}$ value was defined as the concentration of the compounds that inhibited cell proliferation by $50 \%$.

\section{Wound-Scratch Assay}

The effects of casearlucin A on motility ability of HepG2 cells were assessed using wound scratch assay (16). Briefly, cells were seeded into 6 -wells plate with a concentration of $5 \times 10^{5}$ cells/ well. After reaching $90 \%$ confluence, cells were scratched by a sterile pipette tip. Then, the cells were treated with various concentrations of casearlucin A. The wounded healing was observed using microscope at 0 and $48 \mathrm{~h}$. The scratch distance value was measured by Image J software. 


\section{Cell Cycle Analysis}

The distribution of cell cycle of HepG2 cells affected by casearlucin A was performed using Flow cytometric analysis (17). HepG2 cells in exponential growth phase were seeded in 12 well plate at the density of $2 \times 10^{5}$ cells/well for $24 \mathrm{~h}$ at $37^{\circ} \mathrm{C}$. Then, the cells were treated with different concentrations of casearlucin A $(2,4$, and $8 \mu \mathrm{M})$. After an exposure to the test sample for $48 \mathrm{~h}$, the cells were harvested, washed with PBS twice, and fixed in $70 \%$ ice-cold ethanol at $4^{\circ} \mathrm{C}$ overnight. Then, the cells were washed with PBS twice and treated with propidium iodide staining buffer containing RNase (Beyotime, C1052) for 30 minutes at $37^{\circ} \mathrm{C}$ in the dark, followed immediately by cellar DNA analysis using BDLSR Fortessa flow cytometry. Data were processed using ModFit LT Software.

\section{Apoptosis Analysis by Flow Cytometry}

The apoptosis analysis of HepG2 cells induced by the tested compound was accomplished by flow cytometry using Annexin V-FITC Apoptosis Detection Kit (Beyotime, C1062L) according to the manufacturer's instructions $(18,19)$. Briefly, HepG2 cells were harvested and seeded in 12 -well plates $\left(1 \times 10^{5}\right.$ cells/well $)$ and allowed to adhere for $24 \mathrm{~h}$ at $37^{\circ} \mathrm{C}$. Then, the cells were treated with various concentrations $(5,10$, and $15 \mu \mathrm{M})$ of casearlucin A. After $48 \mathrm{~h}$ incubation, the cells were washed twice with PBS and resuspended in the binding buffer (Beyotime, Shanghai, China). This suspension was incubated for $20 \mathrm{~min}$ at room temperature in the dark after adding $10 \mu \mathrm{L}$ Annexin V-FITC and $5 \mu \mathrm{L}$ PI. Then, cell apoptosis was examined by BD LSRFortessa flow cytometry (BD Biosciences). The cell apoptosis data were obtained with FLOWJO flow cytometry analysis software (FLOWJO LLC, Ashland, OR, USA).

\section{Western Blot Analysis}

HepG2 cells were seeded in 6-well plate at the density of $1 \times 10^{5}$ cells/well for $24 \mathrm{~h}$. Then, the cells were treated with casearlucin A for $36 \mathrm{~h}$, the cells were washed with cold PBS twice and collected. The cells were lysed with lysis buffer containing protease inhibitor cocktail and PMSF. Then, the lysates were centrifuged at $10,000 \mathrm{rpm}$ for $10 \mathrm{~min}$ and the supernatants were collected to acquire the total protein. Protein concentrations were quantified using the BCA protein assay kit (Beyotime, P0012S). The proteins were separated by 10\% SDSPAGE and transferred to polyvinylidene difluoride. The membrane was blocked with $5 \%$ skim milk for $1 \mathrm{~h}$ at room temperature and then incubated $\left(4^{\circ} \mathrm{C}\right.$, overnight $)$ with primary antibodies against Bax (Cell Signaling Technology, 14796S), Bcl2 (Cell Signaling Technology, 4223S), FAK (Cell Signaling Technology, 3285S), p-FAK (phospho Y397) (Cell Signaling Technology, 8556S), and MMP-2 (Cell Signaling Technology, 87809S). The membranes were subsequently incubated with horseradish peroxidase-conjugated secondary antibody for $1 \mathrm{~h}$ at room temperature. Lastly, the protein blots were visualized using an ECL detection kit (Beyotime, P0018AS). $\beta$-Actin protein (Cell Signaling Technology, 4970S)was used as an internal reference. Each band was quantified by Image J software (20).

\section{Toxicity Screening of Zebrafish Embryos}

Adult AB strain zebrafish were obtained from School of Medicine, Nankai University (Tianjin, China). Embryos were taken from adult zebrafish, which were placed in the breeding room overnight and mixed for $30 \mathrm{~min}$ to give fertilized eggs. Embryos were cultured in Holt buffer $\left(\mathrm{NaCl} 59.9 \mathrm{mM}, \mathrm{KCl} 0.7 \mathrm{mM}, \mathrm{NaHCO}_{3}\right.$ $0.3 \mathrm{mM}$, and $\mathrm{CaCl}_{2} 0.9 \mathrm{mM}$ ) for further experiments.

The healthy zebrafish embryos were selected and treated with casearlucin A of 2.5, 5, 10, and $20 \mu \mathrm{M}$, to assess the toxicity of the compound on developing zebrafish embryos. The deformity rate and mortality rate were recorded every $24 \mathrm{~h}$ after continuous administration. All the procedures involving animals were approved by the Institutional Animal Care Committee of Nankai University (No. SYXK (JIN) 2019-0001).

\section{Antiangiogenetic Assay Using Transgenic Zebrafish Model}

The angiogenesis inhibitory activity of the selected compound was carried out using transgenic zebrafish $\mathrm{Tg}$ (fli1: EGFP). Transgenic zebrafish were obtained from Shanghai FishBio Co., Ltd. The embryos were obtained from adult $\mathrm{Tg}$ zebrafish as reported previously $(21,22)$. Briefly, 6 hour post fertilization (hpf) embryos were grouped randomly and placed in the 24-well plate, and then the embryos were exposed to various concentrations of casearlucin A for $48 \mathrm{~h}$ at $28.5^{\circ} \mathrm{C}$. After the treatment, embryos were anesthetized with $0.02 \%$ tricaine and photographed by a confocal microscopy (Leica, Germany). The development of intersegmental blood vessels (ISVs) and dorsal longitudinal anastomotic vessels (DLAVs) at $48 \mathrm{hpf}$ were observed, and the length of ISV vessels was measured using Image J software.

\section{In Vivo Anti-Tumor Assay Using Zebrafish Model}

Embryos were obtained from adult $\mathrm{AB}$ zebrafish as reported previously (23). 48 hours post-fertilization (hpf) embryos were utilized to establish a xenograft tumor model (24). Prior to microinjection, HepG2 cells were labeled with $2 \mu \mathrm{M}$ CM-DiI (Yeasen, 40718ES50). Then, the cells were resuspended in serum-free DMEM medium and adjusted to a density of $1 \times$ $10^{7}$ cells/mL. Subsequently, $48 \mathrm{hpf}$ embryos were anesthetized and microinjected into the yolk with $5 \mathrm{~nL}$ stained cells. After $4 \mathrm{~h}$ incubation, tumor-bearing embryos were randomly divided into five groups (15/group) and treated with different concentrations of casearlucin A by soaking. The embryos were incubated continuously for $48 \mathrm{~h}$ at $28.5^{\circ} \mathrm{C}$. Lastly, images were captured at 5 days post-fertilization using a confocal microscopy (Leica, Germany), and the density and focus number of red fluorescence was measured using Image J software.

\section{Statistical Analysis}

Data were analyzed by GraphPad Prism and presented as mean \pm SD. Probabilities (P) less than 0.05 were determined to be significant by analysis of variance (ANOVA). The differences among three or more groups were analyzed by one-way ANOVA multiple comparisons. The experiments were repeated three times. 


\section{RESULTS}

\section{Casearlucin A Inhibited Cancer Cell Growth In Vitro}

In recent years, the potential therapeutic effects of bioactive natural products for cancer treatment have attracted broad attention (4). Thus, we studied the anti-cancer effects of three clerodane diterpenoids (casearlucin A, casearlucin $\mathrm{F}$ and bucidarasin C) from Casearia graveolens. To assess the antiproliferative activity of the compound, three human cancer cell lines (HepG2, A549, and Hela cells) were selected to test their toxicities by MTT assays $(25,26)$. Etoposide was used as a positive control $(27,28)$. Results showed that casearlucin A was the most active and reduced the cell growth in a dosedependent manner (Figure 1). Their respective $\mathrm{IC}_{50}$ values on three cell lines were calculated and shown in Table 1, casearlucin A intensively inhibited the three tumor cell lines with lower $\mathrm{IC}_{50}$ values than etoposide, especially on HepG2 cells.

Next, we further investigated the inhibitory effects of casearlucin A on cell migration, the wounded healing assay was performed $(29,30)$. As shown in Figure 2, after $48 \mathrm{~h}$ treatment of different concentrations of casearlucin $A$, the migration of HepG2 cells were markedly inhibited.

\section{Effects of Casearlucin A on Cell Cycle}

In order to investigate whether casearlucin A inhibited the growth of HepG2 cells by regulating the cell cycle, we first detected its contribution to the induction of cell cycle arrest by flow cytometric analysis $(31,32)$. HepG2 cells were treated with various concentrations of casearlucin $\mathrm{A}$ and then were stained with PI for cell cycle analysis. With the concentrations of casearlucin A increasing from $2 \mu \mathrm{M}$ to $8 \mu \mathrm{M}$, the percentage of cells in the G1 phase increased from $28.9 \%$ (control) to $34.7 \%$ $(2 \mu \mathrm{M}), 39.2 \%(4 \mu \mathrm{M})$, and $52.4 \%(8 \mu \mathrm{M})$, while the $\mathrm{S}$ and $\mathrm{G} 2$ phase decreased after treated with different concentrations (Figure 3). Collectively, these results implied that casearlucin A could induce G0/G1 cell cycle arrest in HepG2 cells.

\section{Apoptosis Effects Induced by Casearlucin A}

Then, the effects of casearlucin A on cell apoptosis were investigated in HepG2 cells. We analyzed the apoptosis by flow cytometry using Annexin V/PI double staining (33, 34). As shown in Figure 4, we found that the population of the early and late apoptotic cells increased dramatically. With the increase of concentrations of casearlucin A, the percentage of apoptotic cells rose from $8.0 \%$ (control) to $37.4 \%(5 \mu \mathrm{M}), 67.2 \%(10 \mu \mathrm{M})$ and $79.3 \%(15 \mu \mathrm{M})$. The data indicated that the apoptosis of HepG2 cells induced by casearlucin A was dose-dependent. As a result, casearlucin A was proven to possess strong apoptotic induction abilities against HepG2 cells.

Moreover, since the Bcl-2 family proteins are the key regulators of mitochondrial membrane function, which have pivotal roles in the regulation of mitochondrial apoptosis. We examined the effects of casearlucin A on the expression of antiapoptotic Bcl-2 protein, and pro-apoptotic Bax protein. As the results illustrated in Figure 5, casearlucin A treatment increased the protein levels of Bax, and decreased the protein levels of Bcl-2.

\section{Casearlucin A Inhibited HepG2 Cell Metastasis via Regulating FAK/MMPs Signaling Pathway}

In order to further reveal the mechanism of casearlucin A inhibiting cell metastasis, a few of metastasis-related proteins were detected after $36 \mathrm{~h}$ treatment $(35,36)$. Many studies have reported that matrix-metalloproteinases (MMPs) play key roles in tumor progression and metastasis, tumor cells usually have high expression levels of MMP. Our results revealed that the protein expression level of MMP-2 in HepG2 cells was obviously reduced in a dose-dependent manner after casearlucin A treatment (Figure 6). Then, the mechanism underlying casearlucin Ainduced downregulation of MMP-2 expression in HepG2 cells was investigated, and accumulating evidence have demonstrated that the phosphorylation at Tyr 397 of FAK could promote the combination between FAK and PI3K, which in turn activated Akt, ultimately increased the MMPs. Thus, as shown in Figure 6, we further confirmed that the phosphorylation of FAK was decreased when HepG2 cells were treated with casearlucin A.

\section{Toxicity Screening of Casearlucin A to Zebrafish Embryos}

The zebrafish embryos were treated with casearlucin A (2.5 to 20 $\mu \mathrm{M})$ for $48 \mathrm{~h}$. As shown in Figure 7, the morphology of zebrafish was healthy without deformity, tail dysplasia, and yolk enlargement under the concentration of 2.5-20 $\mu \mathrm{M}$. Hence,
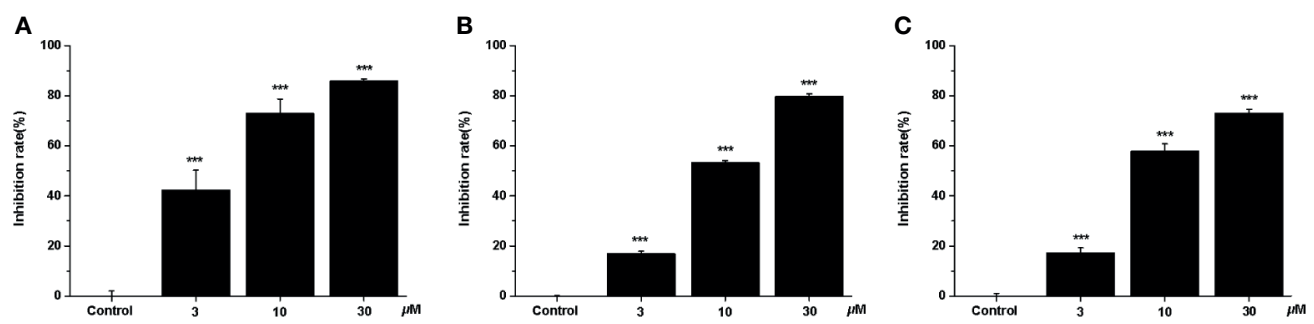

FIGURE 1 | Anti-proliferative effects of casearlucin A treatment on three cell lines. HepG2 (A), A549 (B) and Hela (C) cells were treated with casearlucin A (3, 10, and $30 \mu \mathrm{M}$ ) for $48 \mathrm{~h}$. Cell viability was examined using MTT assay. DMSO was used as a negative control. The results are presented as means \pm SD. ${ }^{\star \star \star} p<0.001$ versus control group. 
TABLE 1 | Cytotoxicities of three compounds against three human cancer cell lines.

\begin{tabular}{|c|c|c|c|}
\hline Compound & HepG2 $\left(\mathrm{IC}_{50}, \mu \mathrm{M}\right)$ & A549 $\left(\mathrm{IC}_{50}, \mu \mathrm{M}\right)$ & Hela $\left(\mathrm{IC}_{50}, \mu \mathrm{M}\right)$ \\
\hline Casearlucin A & $3.8 \pm 0.3$ & $9.9 \pm 0.1$ & $10.5 \pm 0.8$ \\
\hline Casearlucin F & $9.1 \pm 0.9$ & $17.1 \pm 1.8$ & $15.6 \pm 1.1$ \\
\hline Bucidarasin C & $10.2 \pm 1.0$ & $16.6 \pm 0.7$ & $7.2 \pm 0.2$ \\
\hline Etoposide $^{\mathrm{a}}$ & $15.7 \pm 1.6$ & $42.7 \pm 2.7$ & $31.0 \pm 0.7$ \\
\hline
\end{tabular}

${ }^{a}$ Etoposide was used as a positive control. All results are expressed as mean $\pm S D$.
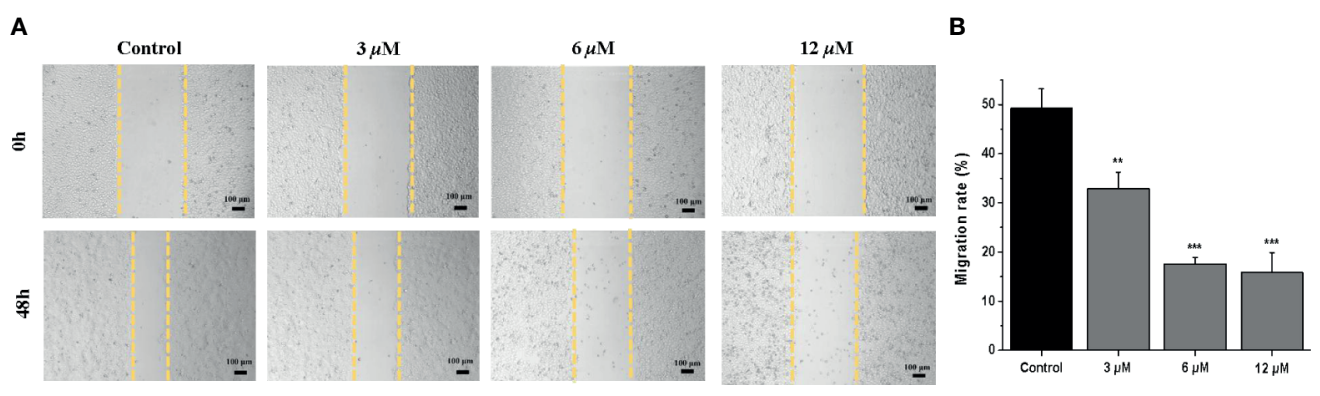

FIGURE 2 | Casearlucin A inhibited HepG2 cells in wounded healing assay. (A) HepG2 cells were photographed at $0 \mathrm{~h}$ and $48 \mathrm{~h}$ (scale bar: 100 mm). Data of Migration rate (\%) were shown in (B). DMSO was used as a negative control. The results are presented as means \pm SD. ${ }^{\star \star} p<0.01$, and ${ }^{\star \star *} p<0.001$ versus control group.

there was no toxicity to zebrafish after the treatment of casearlucin A $(2.5-20 \mu \mathrm{M})$. Based on the results, the concentrations of $5,10,20 \mu \mathrm{M}$ were selected for further in vivo research.

\section{Antiangiogenetic Activity of Casearlucin A Using a Transgenic Zebrafish Model}

In this study, the effects of casearlucin A on zebrafish intersegmental vessels formation were examined. Herein, we used the transgenic zebrafish embryos to directly visualize the effect of casearlucin A on the new vessel development $(37,38)$. As shown in Figure 8, in contrast with the blank control, the intersegmental vessels (ISVs) and dorsal longitudinal anastomotic vessels (DLAVs) were absent and broken after treatment with casearlucin A and the positive control, sunitinib malate. According to the satanical results, the average length of ISVs of the control group was $2654.9 \mu \mathrm{m}$, and the length decreased in a dose-dependent manner $(2119.0 \pm 137.7 \mu \mathrm{m}$ at $5 \mu \mathrm{M}, 1542.6 \pm 126.4 \mu \mathrm{m}$ at $10 \mu \mathrm{M}$, and $1232.0 \pm 74.6 \mu \mathrm{m}$ at 20 $\mu \mathrm{M})$ with the increase of concentrations of casearlucin A.

\section{In Vivo Anti-Tumor Activity of Casearlucin A Using a Zebrafish Model}

Previous studies showed that casearlucin A exhibited cytotoxic activity to three human tumor cells in vitro, and markedly inhibited the migration of HepG2 cells. Thus, we examined whether the compound could block HepG2 cells proliferation in zebrafish xenograft tumor model $(39,40)$. HepG2 cells labeled with CM-DiI were microinjected into the yolk sac of $48 \mathrm{hpf}$ embryos, and examined by fluorescence microscopy. As presented in Figure 9, treatment with casearlucin A significantly decreased cell proliferation and migration, and the compound showed inhibition effects in dose-dependent manners. The results showed that casearlucin A effectively blocked tumor cell invasion and metastasis, which was comparable to the positive control, etoposide.

\section{CONCLUSION AND DISCUSSION}

As numerous studies reported, because of its abnormal proliferation and high invasiveness, the treatment of cancer is very difficult. A key feature of tumor proliferation and metastasis processes is abnormal angiogenesis. Thus, the therapeutic agents targeting these characteristics will be more effective.

In our study, we have taken out a series of experiments to detect the effects of casearlucin A on cancer cell proliferation and migration in vitro. The results showed that casearlucin A exhibited the cytotoxicity against the selected cancer cell lines and possessed the most cytotoxic effects against HepG2 cells with an $\mathrm{IC}_{50}$ value of $3.8 \mu \mathrm{M}$. Meanwhile, the wound healing assay indicated that HepG2 cells showed a migration inhibition tendency after treated by casearlucin A. Furthermore, we used zebrafish as a powerful and reliable preclinical animal model to further study the inhibitory activity of casearlucin A on the proliferation and metastasis of HepG2 cells, which revealed the anti-tumor activity in vivo of casearlucin A. Taken together, the in vitro and in vivo promising results suggested that the mechanism of casearlucin A should be further assessed.

The subsequent preliminary mechanism investigation revealed that casearlucin $\mathrm{A}$ induced the apoptosis and arrested 

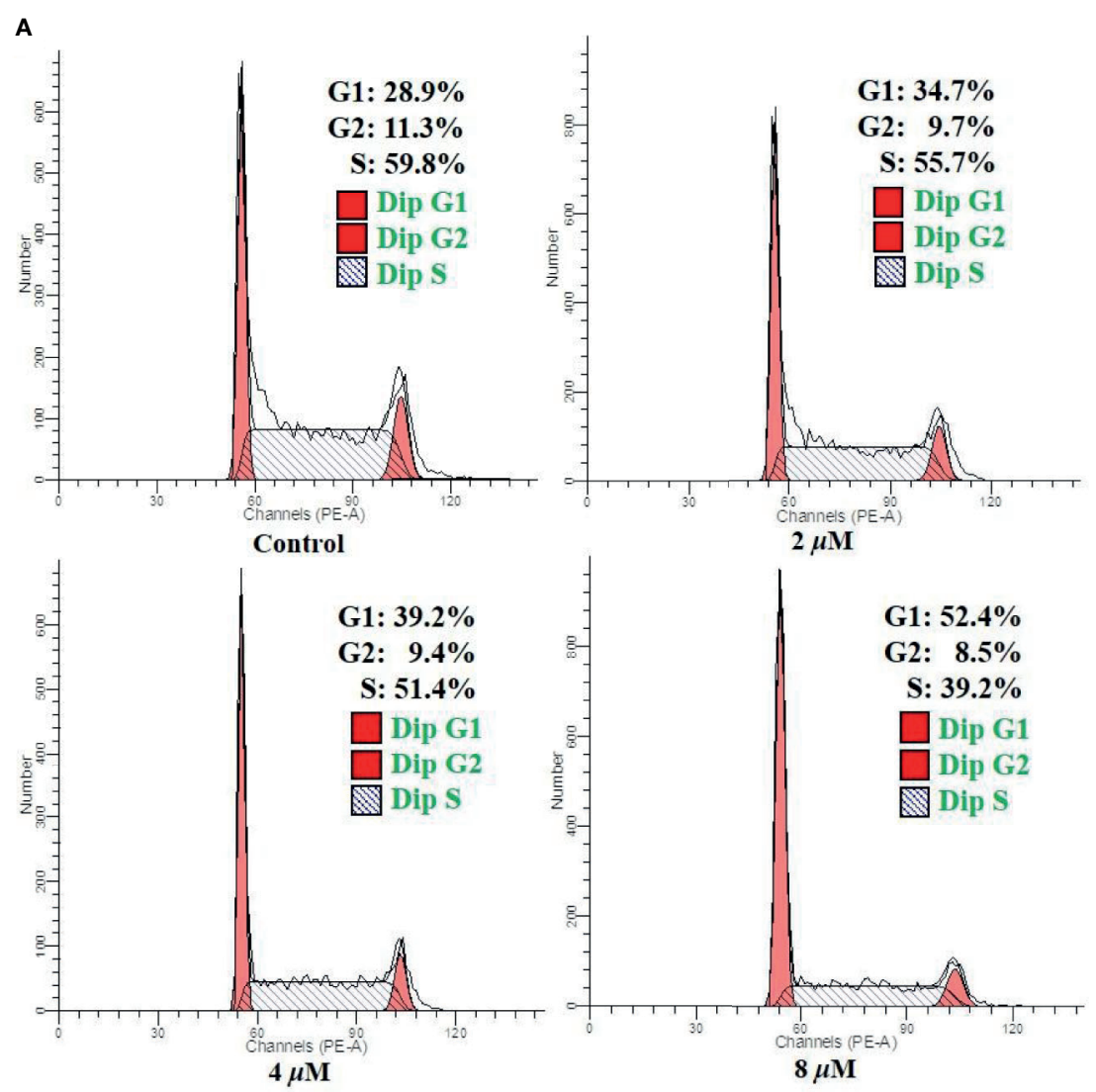

B

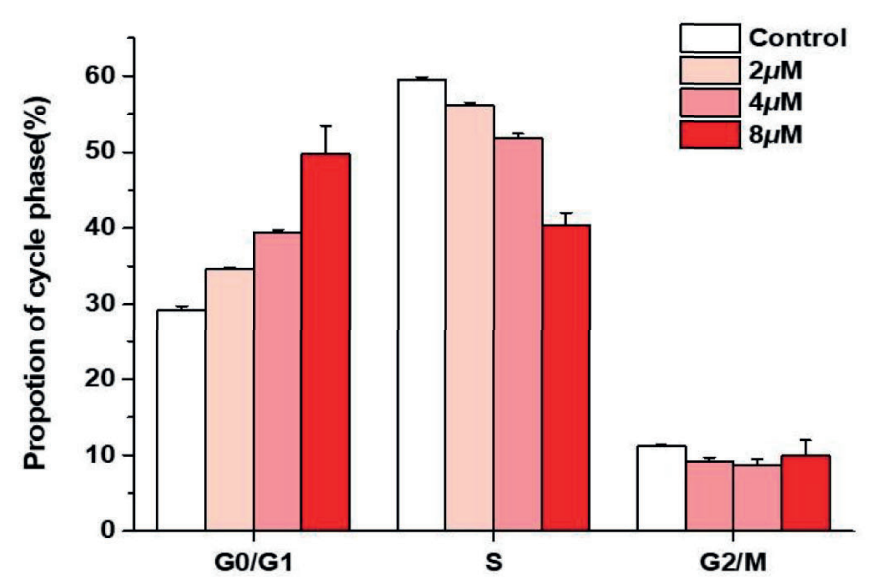

FIGURE 3 | Arrest effects of casearlucin A on HepG2 cell cycle. HepG2 cells were treated with different concentrations (2, 4, and $8 \mu \mathrm{M})$ of casearlucin A for $48 \mathrm{~h}$. DMSO was used as a negative control. (A) The cells were harvested and stained with propidium iodide (PI), and the cell cycle distribution was analyzed using flow cytometry. (B) Data processing of cell cycle distribution. Data from three separate experiments are expressed as means \pm SD.

the HepG2 cell cycle at the G0/G1 stage to exert cytotoxic effects. Moreover, we examined the expression levels of the representative proteins associated with cell apoptosis. It has been reported that the proteins of Bcl-2 family play a vital role in the mitochondria-mediated apoptosis pathway. In our study, the inhibition of $\mathrm{Bcl}-2$ expression and the increase in Bax protein level by casearlucin A, demonstrated that the compound could promote apoptosis by targeting mitochondrial pathway.

In addition, FAK/MMPs signaling pathway had been proved to play critical roles in cancer cell migration and invasion. As we all know,, over-expressed FAK protein participates in the formation of focal adhesions and activates signaling pathways 


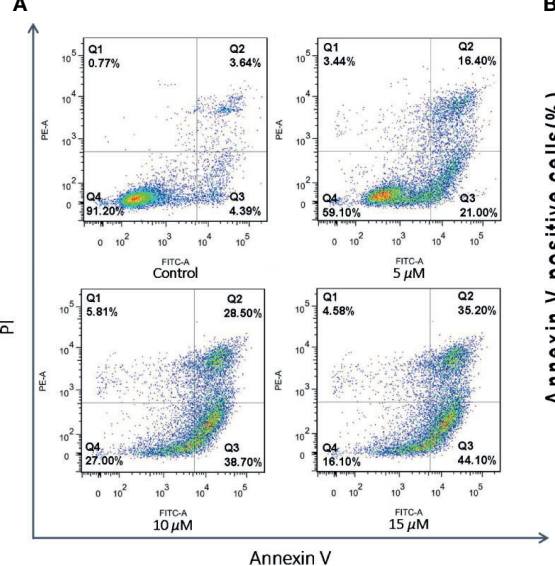

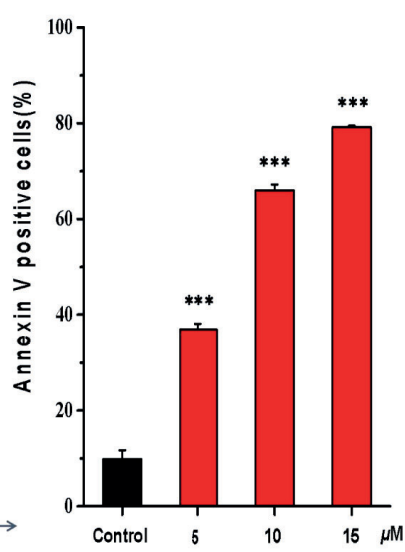

FIGURE 4 | Apoptosis effects of HepG2 cells induced by casearlucin A. HepG2 cells were treated with different concentrations (5, 10, and 15 $\mu$ M) of casearlucin A for $48 \mathrm{~h}$. DMSO was used as a negative control. Then, the cells were harvested, stained with Annexin $\mathrm{V}$ and propidium iodide (PI), and subsequently analyzed by flow cytometry. (A) Flow cytometric analysis of HepG2 cells after treated with different concentrations of casearlucin A. (B) Histogram of apoptotic cells at $48 \mathrm{~h}$ with the treatment of casearlucin A. Data from three separate experiments are expressed as means $\pm S D$. ${ }^{\star \star \star} p<0.001$ versus control group.

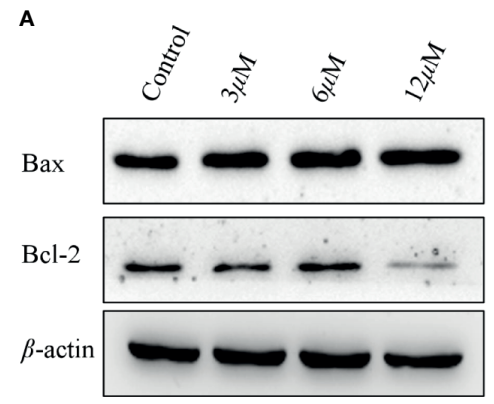

B

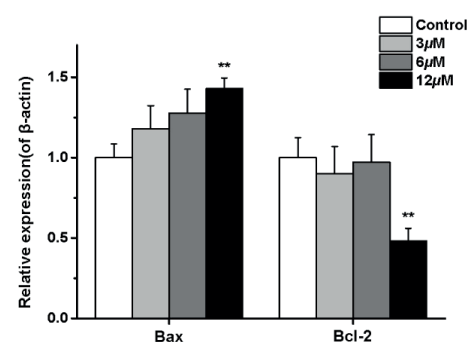

FIGURE 5 | Effects of casearlucin A on apoptosis related proteins expression in HepG2 cells. HepG2 cells were pre-treated with casearlucin A for 36 h, and western blotting analysis was performed. DMSO was used as a negative control. (A) Western blotting results of protein levels. (B) Quantitative analysis of apoptosis related proteins expression. $\beta$-Actin protein was used as internal reference. ${ }^{\star \star} p<0.01$ compared with control group cells. Data were obtained by at least three independent experiments.
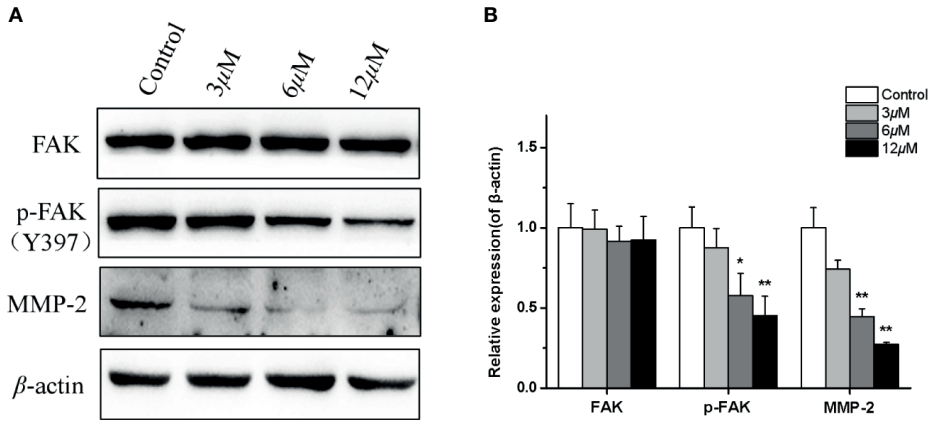

FIGURE 6 | Effects of casearlucin A on metastasis-related proteins expression in HepG2 cells. HepG2 cells were pre-treated with casearlucin A for 36 h, and western blotting analysis was performed. DMSO was used as a negative control. (A) Western blotting results of protein levels. (B) Quantitative analysis of metastasisrelated proteins expression. $\beta$-Actin protein was used as an internal reference. ${ }^{*} p<0.05$, and ${ }^{* *} p<0.01$ compared with control group cells. Data were obtained by at least three independent experiments. 
A
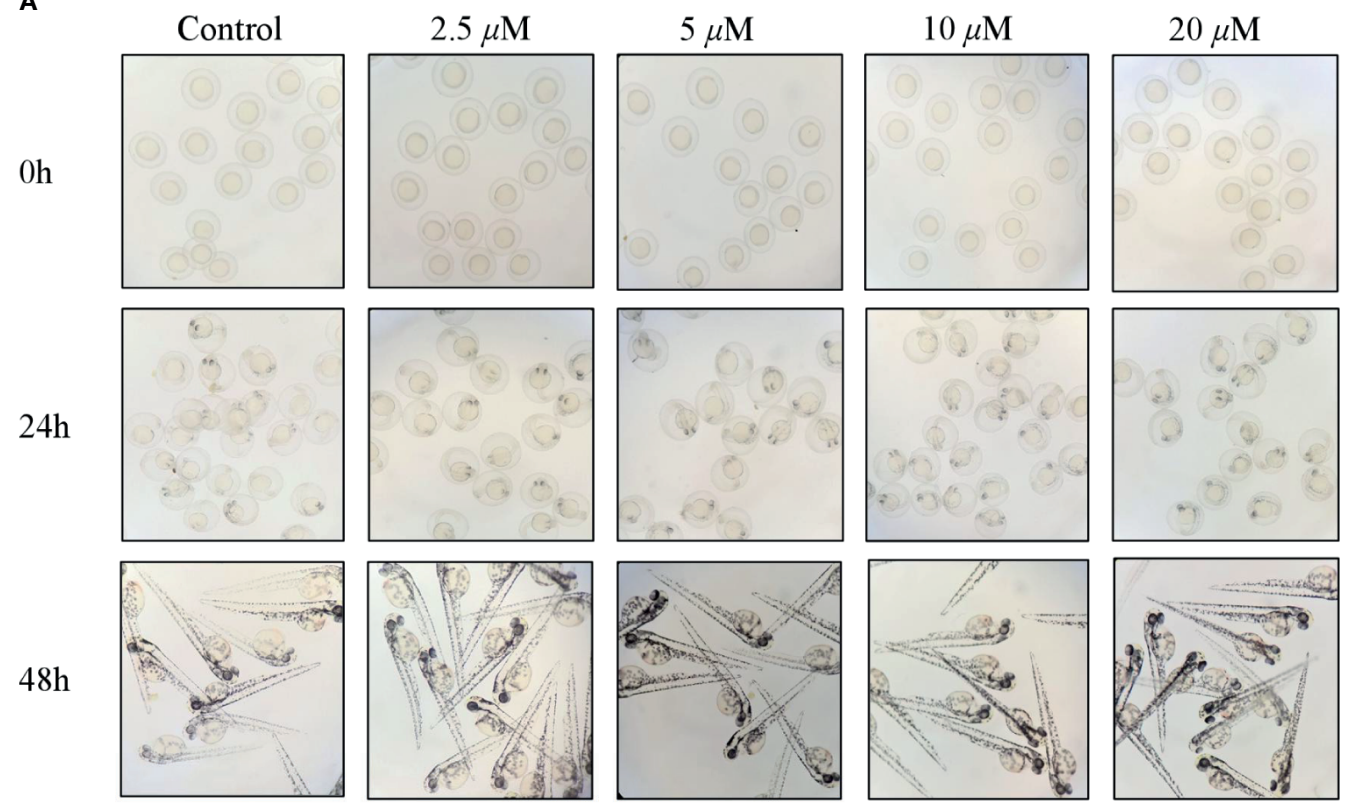

B

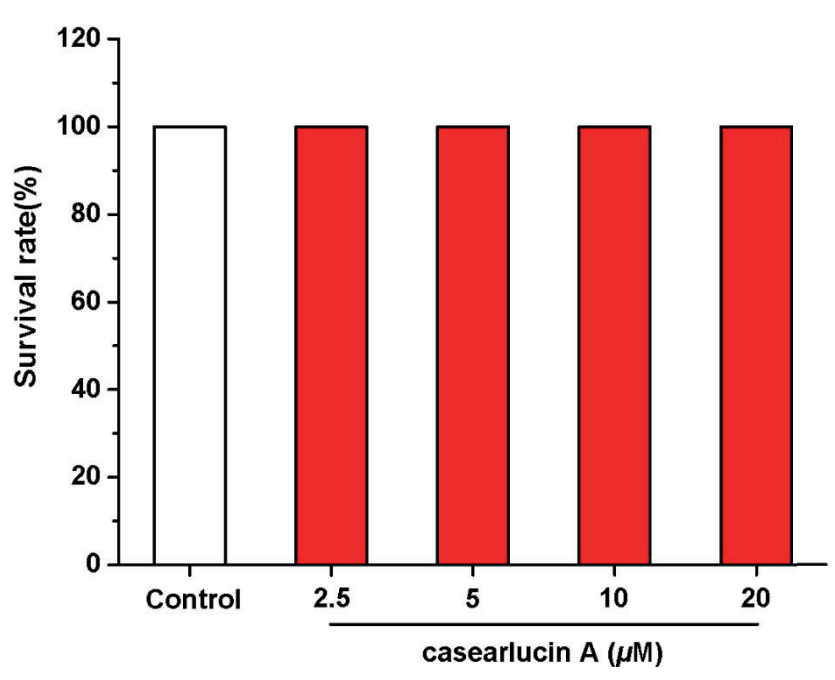

FIGURE 7 | Developmental toxicity of casearlucin A in Zebrafish Embryos. The zebrafish embryos were treated with casearlucin A (2.5, 5, 10, and $20 \mu \mathrm{M})$ for $48 \mathrm{~h}$. (A) The morphology of zebrafish. (B) The survival rate of zebrafish. DMSO was used as a negative control.

related to proliferation, cell migration, and angiogenesis. Furthermore, many studies have reported that matrixmetalloproteinases (MMPs) are overexpressed in almost all cancer types of cancer, and play key roles in the cancer progression and aggression $(41,42)$. While, as a major kinase of focal adhesion, in this process, the phosphorylation at Tyr 397 of FAK could promote the combination between FAK and PI3K, ultimately increasing the MMPs (43). Our results revealed that casearlucin A treatment decreased the phosphorylation of FAK, and the protein expression level of MMP-2 was obviously reduced in a dose-dependent manner.

Moreover, the abnormal angiogenesis is a key feature of tumor proliferation and metastasis, and thus, angiogenesis is considered as an attractive target for cancer therapeutic strategy. In our study, we used the transgenic zebrafish embryos to directly demonstrate its anti-angiogenic $T g$ (fli1: EGFP) activity.

For a long time, the favorable efficacy and low side effect of phytochemicals promoted people to seek for anti-cancer drug candidates from natural source. In our study, casearlucin A had stronger cytotoxic activity than the positive control etoposide, and there was no toxicity to zebrafish embryo development under the concentration of $2.5-20 \mu \mathrm{M}$. With the in-depth research, the potential pharmacological effects and mechanism had been evaluated. In conclusion, casearlucin A may be a novel chemotherapeutic drug for cancer by inhibiting cell proliferation and migration and blocking angiogenesis. 
A
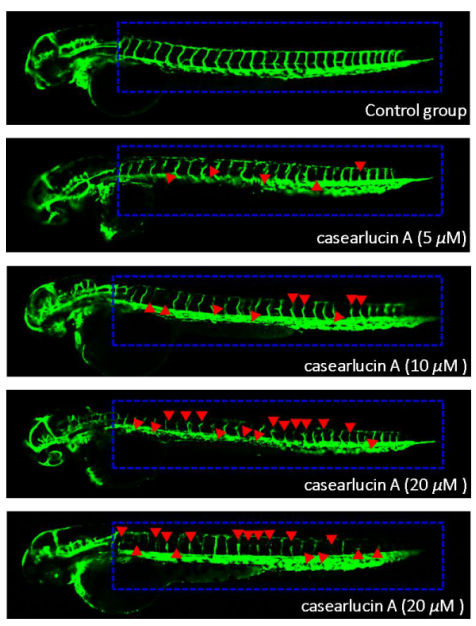

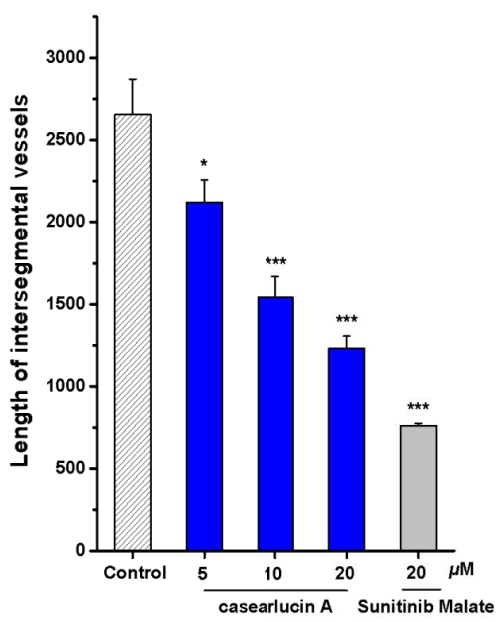

FIGURE 8 | Anti-angiogenesis activity of casearlucin A in transgenic zebrafish model. The embryos from transgenic zebrafish $T g$ (fli1: EGFP) were treated by the tested compound and the anti-angiogenetic compound, sunitinib malate (positive control). DMSO was used as a negative control. After exposure to the compounds for $48 \mathrm{~h}$, the development of intersegmental vessels (ISVs) and dorsal longitudinal anastomotic vessels (DLAVs) were observed, and the length of ISV vessels was measured using ImageJ program. (A) Representative images of zebrafish embryos treated with vehicle, casearlucin A, and sunitinib malate. (B) The average length of ISVs of zebrafish after treated with different concentrations of casearlucin $\mathrm{A}(5,10$, and $20 \mu \mathrm{M})$. ( $\mathrm{n}=15$ for each experimental group). ${ }^{*} p<0.5,{ }^{* \star *} p<0.001$ versus control group.
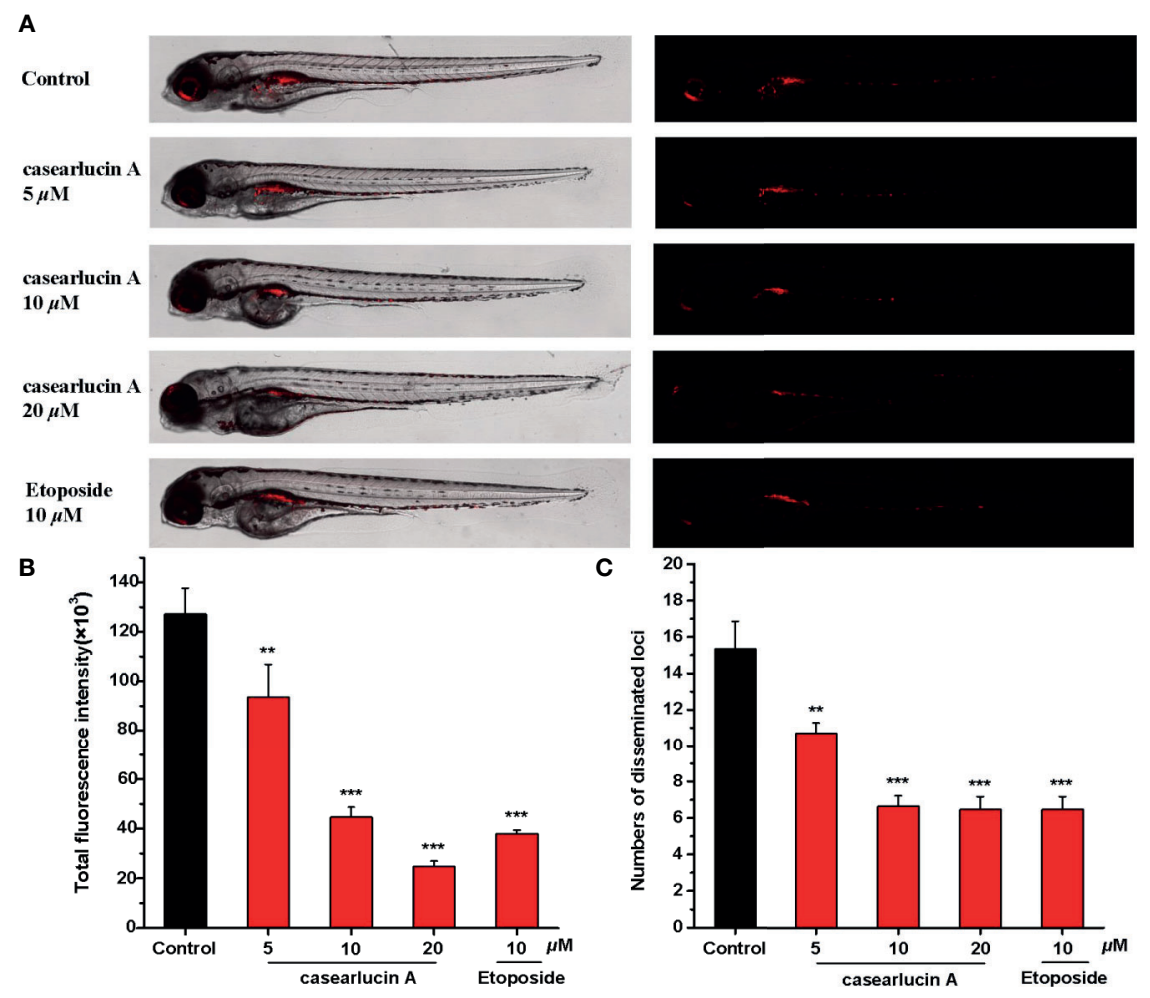

FIGURE 9 | In vivo anti-tumor effects of casearlucin A in zebrafish xenografts. CM-Dil stained HepG2 cells were transplanted into 2 dpf zebrafish embryos by microinjecting. $4 \mathrm{~h}$ later, tumor-bearing embryos were treated with casearlucin A (5, 10, and $20 \mu \mathrm{M}$ ) and etoposide (10 $\mu \mathrm{M})$ for $48 \mathrm{~h}(\mathrm{n}=15 / \mathrm{group})$. DMSO was used as a negative control. (A)Intensity and distribution of the red fluorescence were imaged under a confocal microscope. (B) Fluorescence intensity of the tumor xenografts, representing the number of HepG2 cells. (C) Quantification of the fluorescent area of the tumor xenografts, representing HepG2 cell metastasis. Results are expressed as means \pm SD. ${ }^{* *} p<0.01$ and ${ }^{\star * *} p<0.001$ versus control group. 


\section{DATA AVAILABILITY STATEMENT}

The original contributions presented in the study are included in the article/supplementary material. Further inquiries can be directed to the corresponding authors.

\section{ETHICS STATEMENT}

The animal study was reviewed and approved by Experimental animal ethics committee of Nankai University.

\section{AUTHOR CONTRIBUTIONS}

JX \& YG: Designing the experiments and directing the study. YiL: Performing the experiments, analyzing the data, and writing

\section{REFERENCES}

1. Bray F, Ferlay J, Soerjomataram I, Siegel RL, Torre LA, Jemal A. Global Cancer Statistics 2018: GLOBOCAN Estimates of Incidence and Mortality Worldwide for 36 Cancers in 185 Countries. CA: Cancer J Clin (2018) 68:394424. doi: $10.3322 /$ caac. 21492

2. Torre LA, Siegel RL, Ward EM, Jemal A. Global Cancer Incidence and Mortality Rates and Trends-An Update. Cancer Epidem Biomar (2016) 25:16-27. doi: 10.1158/1055-9965.EPI-15-0578

3. Lichota A, Gwozdzinski K. Anticancer Activity of Natural Compounds From Plant and Marine Environment. Int J Mol Sci (2018) 19:3533. doi: 10.3390/ ijms19113533

4. Huang MY, Zhang LL, Ding J, Lu JJ. Anticancer Drug Discovery From Chinese Medicinal Herbs. Chin Med UK (2018) 13:35. doi: 10.1186/s13020018-0192-y

5. Xia L, Guo Q, Tu PF, Chai XY. The Genus Casearia: A Phytochemical and Pharmacological Overview. Phytochem Rev (2015) 14:99-135. doi: 10.1007/ s11101-014-9336-6

6. Ferreira PM, Militao GC, Lima DJ, Costa ND, Machado KC, Santos AG, et al. Morphological and Biochemical Alterations Activated by Antitumor Clerodane Diterpenes. Chem Biol Interact (2014) 222:112-25. doi: 10.1016/ j.cbi.2014.10.015

7. Nguyen HT, Truong NB, Doan HT, Litaudon M, Retailleau P, Do TT, et al. Cytotoxic Clerodane Diterpenoids From the Leaves of Casearia Grewiifolia. Pham J Nat Prod (2015) 78:2726-30. doi: 10.1021/acs.jnatprod.5b00677

8. Vieira-Júnior GM, Dutra LA, Ferreira PM, de Moraes MO, Costa Lotufo LV, Pessoa Cdo O, et al. Cytotoxic Clerodane Diterpenes From Casearia Rupestris. J Nat Prod (2011) 74:776-81. doi: 10.1021/np100840w

9. Wang B, Wang XL, Wang SQ, Shen T, Liu YQ, Yuan HQ, et al. Cytotoxic Clerodane Diterpenoids From the Leaves and Twigs of Casearia Balansae. J Nat Prod (2013) 76:1573-9. doi: 10.1021/np400212d

10. Whitson EL, Thomas CL, Henrich CJ, Sayers TJ, Mcmahon JB, Mckee TC, et al. Clerodane Diterpenes From Casearia Arguta That Act As Synergistic TRAIL Sensitizers. J Nat Prod (2010) 73:2013-8. doi: 10.1021/np1004455

11. Xu J, Ji FF, Sun XC, Cao XR, Li S, Ohizumi Y, et al. Characterization and Biological Evaluation of Diterpenoids From Casearia Graveolens. J Nat Prod (2015) 78:2648-56. doi: 10.1021/acs.jnatprod.5b00583

12. Xu J, Kang J, Sun XC, Cao XR, Rena K, Lee D, et al. Di- and Triterpenoids From the Leaves of Casearia Balansae and Neurite Outgrowth Promoting Effects of PC12 Cells. J Nat Prod (2016) 79:170-9. doi: 10.1021/acs.jnatprod.5b00815

13. Xu JJ, Wu X, Li MM, Li GQ, Yang YT, Luo HJ, et al. Antiviral Activity of Polymethoxylated Flavones From "Guangchenpi”, the Edible and Medicinal Pericarps of Citrus Reticulata 'Chachi'. J Nat Prod (2014) 77:2182-9. doi: $10.1021 /$ jf $404310 \mathrm{y}$

14. Liu F, Ma J, Shi ZY, Zhang Q, Wang HM, Li DH, et al. Clerodane Diterpenoids Isolated From the Leaves of Casearia Graveolens. J Nat Prod (2020) 83:36-44. doi: 10.1021/acs.jnatprod.9b00515 the original draft preparation. JM: Performing the extraction, purification, and structure identification of casearlucin A. ZS, YZ, HZ \& YeL: Reviewing and revising the manuscript. All authors contributed to the article and approved the submitted version.

\section{FUNDING}

This research was supported financially by the National Natural Science Foundation of China (Nos. 22077067 and U1801288), the Natural Science Foundation of Tianjin, China (No. 19JCYBJC28100), Hundred Young Academic Leaders Program of Nankai University, and the Fundamental Research Funds for the Central Universities, Nankai University (No. 63201236).

15. Li DH, Li JY, Xue CM, Han T, Sai CM, Wang KB. Antiproliferative Dimeric Aporphinoid Alkaloids From the Roots of Thalictrum Cultratum. J Nat Prod (2017) 80:2893-904. doi: 10.1021/acs.jnatprod.7b00387

16. Fan ZJ, Xu Q, Wang CH, Lin XK, Zhang QB, Wu N. A Tropomyosin-Like Meretrix Meretrix Linnaeus Polypeptide Inhibits the Proliferation and Metastasis of Glioma Cells Via Microtubule Polymerization and FAK/Akt/MMPs Signaling. Int J Biol Macromol (2020) 145:154-64. doi: 10.1016/j.ijbiomac.2019.12.158

17. Guo LM, Cui J, Wang HR, Medina R, Zhang SL, Zhang XH, et al. Metformin Enhances Anti-Cancer Effect of Cisplatin in Meningioma Through AMPKmTOR Signaling Pathways. Mol Ther Oncolytics (2021) 20:119-31. doi: 10.1016/j.omto.2020.11.004

18. Wei LY, Yang Y, Gupta P, Wang A, Zhao M, Zhao Y, et al. A Small Molecule Inhibitor, Ogp46, Is Effective Against Imatinib-Resistant Bcr-Abl Mutations Via the BCR-ABL/JAK-STAT Pathway. Mol Ther Oncolytics (2020) 18:13748. doi: 10.1016/j.omto.2020.06.008

19. Wu Z, Li H, Wang YD, Yang DJ, Tan HJ, Zhan Y, et al. Optimization Extraction, Structural Features and Antitumor Activity of Polysaccharides From Z. Jujuba Cv. Ruoqiangzao Seeds. Int J Biol Macromol (2019) 135:115161. doi: 10.1016/j.ijbiomac.2019.06.020

20. Wang B, Ding YM, Fan P, Wang B, Xu JH, Wang WX. Expression and Significance of MMP2 and HIF-1alpha in Hepatocellular Carcinoma. Oncol Lett (2014) 8:539-46. doi: 10.3892/ol.2014.2189

21. Wang HL, Li YM, Shi G, Wang Y, Lin Y, Wang Q, et al. A Novel Antitumor Strategy: Simultaneously Inhibiting Angiogenesis and Complement by Targeting VEGFA/PIGF and C3b/C4b. Mol Ther Oncolytics (2020) 16:2029. doi: 10.1016/j.omto.2019.12.004

22. Hsu WJ, Lin MH, Kuo TC, Chou CM, Mi FL, Cheng CH, et al. Fucoidan From Laminaria Japonica Exerts Antitumor Effects on Angiogenesis and Micrometastasis in Triple-Negative Breast Cancer Cells. Int J Biol Macromol (2020) 149:600608. doi: 10.1016/j.ijbiomac.2020.01.256

23. Mazumder A, Lee JY, Talhi O, Cerella C, Chateauvieux S, Gaigneaux A, et al Hydroxycoumarin OT-55 Kills CML Cells Alone or in Synergy With Imatinib or Synribo: Involvement of ER Stress and DAMP Release. Cancer Lett (2018) 438:197-218. doi: 10.1016/j.canlet.2018.07.041

24. Tseng CH, Chen YR, Tzeng CC, Liu W, Chou CK, Chiu CC, et al. Discovery of Indeno[1,2-B]Quinoxaline Derivatives as Potential Anticancer Agents. Eur J Med Chem (2016) 108:258-73. doi: 10.1016/j.ejmech.2015.11.031

25. Ma J, Cui Y, Cao T, Xu H, Shi Y, Xia J, et al. PDS5B Regulates Cell Proliferation and Motility Via Upregulation of Ptch2 in Pancreatic Cancer Cells. Cancer Lett (2019) 460:65-74. doi: 10.1016/j.canlet.2019.06.014

26. Yu JS, Lee D, Lee SR, Lee JW, Choi CI, Jang TS, et al. Chemical Characterization of Cytotoxic Indole Acetic Acid Derivative From Mulberry Fruit (Morus Alba L.) Against Human Cervical Cancer. Bioorg Chem (2018) 76:28-36. doi: 10.1016/j.bioorg.2017.10.015

27. Mirzaei H, Shokrzadeh M, Modanloo M, Ziar A, Riazi GH, Emami S. New Indole-Based Chalconoids as Tubulin-Targeting Antiproliferative Agents. Bioorg Chem (2017) 75:86-98. doi: 10.1016/j.bioorg.2017.09.005 
28. Pertuit D, Larshini M, Brahim MA, Markouk M, Mitaine-Offer AC, Paululat T, et al. Triterpenoid Saponins From the Roots of Spergularia Marginata. Phytochemistry (2017) 139:81-7. doi: 10.1016/j.phytochem.2017.03.007

29. Liang CC, Park AY, Guan JL. In Vitro Scratch Assay: A Convenient and Inexpensive Method for Analysis of Cell Migration In Vitro. Nat Protoc (2007) 2:329-33. doi: 10.1038/nprot.2007.30

30. Lu WL, Yang T, Song QJ, Fang ZQ, Pan ZQ, Liang C, et al. Akebia Trifoliata (Thunb.) Koidz Seed Extract Inhibits Human Hepatocellular Carcinoma Cell Migration and Invasion In Vitro. J Ethnopharmacol (2018) 234:204-15. doi: 10.1016/j.jep.2018.11.044

31. Dong XD, Yu J, Feng YY, Ji HY, Yu SS, Liu AJ. Alcohol-soluble Polysaccharide From Castanea Mollissima Blume: Preparation, Characteristics and Antitumor Activity. J Funct Foods (2019) 63:103563. doi: 10.1016/j.jff.2019.103563

32. Hou Y, Pi C, Feng X, Wang Y, Fu S, Zhang X, et al. Antitumor Activity In Vivo and Vitro of New Chiral Derivatives of Baicalin and Induced Apoptosis Via the PI3K/Akt Signaling Pathway. Mol Ther Oncolytics (2020) 19:6778. doi: 10.1016/j.omto.2020.08.018

33. Hu X, Jiao RW, Li HN, Wang XH, Lyu HD, Gao X, et al. Antiproliferative Hydrogen Sulfide Releasing Evodiamine Derivatives and Their Apoptosis Inducing Properties. Eur J Med Chem (2018) 151:376-88. doi: 10.1016/ j.ejmech.2018.04.009

34. Dong XD, Feng YY, Liu YN, Ji HY, Yu SS, Liu AJ, et al. A Novel Polysaccharide From Castanea Mollissima Blume: Preparation, Characteristics and Antitumor Activities In Vitro and In Vivo. Carbohyd Polym (2020) 240:116323. doi: 10.1016/j.carbpol.2020.116323

35. Shao M, Lou DD, Yang JB, Lin MT, Deng XH, Fan Q. Curcumin and Wikstroflavone B, a New Biflavonoid Isolated From Wikstroemia Indica, Synergistically Suppress the Proliferation and Metastasis of Nasopharyngeal Carcinoma Cells Via Blocking FAK/STAT3 Signaling Pathway. Phytomedicine (2020) 79:153341. doi: 10.1016/j.phymed.2020.153341

36. Zheng QQ, Diao S, Wang Q, Zhu C, Sun X, Yin B, et al. Il-17A Promotes Cell Migration and Invasion of Glioblastoma Cells Via Activation of PI3K/AKT Signalling Pathway. J Cell Mol Med (2019) 23:357-69. doi: 10.1111/ jcmm. 13938

37. Alqahtani AS, Nasr FA, Noman OM, Farooq M, Alhawassi T, Qamar W, et al. Cytotoxic Evaluation and Anti-Angiogenic Effects of Two Furano-
Sesquiterpenoids From Commiphora Myrrh Resin. Molecules (2020) 25:1318. doi: 10.3390/molecules 25061318

38. Petrović J, Glamočlija J, Ilić-Tomić T, Soković M, Robajac D, Nedić O, et al. Lectin From Laetiporus Sulphureus Effectively Inhibits Angiogenesis and Tumor Development in the Zebrafish Xenograft Models of Colorectal Carcinoma and Melanoma. Int J Biol Macromol (2020) 148:129-39. doi: 10.1016/j.ijbiomac.2020.01.033

39. Wu JQ, Fan RY, Zhang SR, Li CY, Shen LZ, Wei P, et al. A Systematical Comparison of Anti-Angiogenesis and Anti-Cancer Efficacy of Ramucirumab, Apatinib, Regorafenib and Cabozantinib in Zebrafish Model. Life Sci (2020) 247:117402. doi: 10.1016/j.lfs.2020.117402

40. Tu WM, Huang XC, Chen YL, Luo YL, Liau I, Hsu HY. Longitudinal and Quantitative Assessment Platform for Concurrent Analysis of Anti-Tumor Efficacy and Cardiotoxicity of Nano-Formulated Medication In Vivo. Anal Chim Acta (2020) 1095:129-37. doi: 10.1016/j.aca.2019.10.019

41. Lu PF, Weaver VM, Werb Z. The Extracellular Matrix: A Dynamic Niche in Cancer Progression. J Cell Biol (2012) 196:395-406. doi: 10.1083/ jcb.201102147

42. Paw I, Carpenter RC, Watabe K, Debinski W, Lo HW. Mechanisms Regulating Glioma Invasion. Cancer Lett (2015) 362:1-7. doi: 10.1016/ j.canlet.2015.03.015

43. Liu XJ, Wu X, Wang YM, Li YH, Chen XL, Yang WC, et al. CD47 Promotes Human Glioblastoma Invasion Through Activation of the PI3K/Akt Pathway. Oncol Res (2019) 27:415-22. doi: 10.3727/096504018x15155538502359

Conflict of Interest: The authors declare that the research was conducted in the absence of any commercial or financial relationships that could be construed as a potential conflict of interest.

Copyright (c) $2021 \mathrm{Li}, \mathrm{Ma}$, Song, Zhao, Zhang, Li, Xu and Guo. This is an open-access article distributed under the terms of the Creative Commons Attribution License (CC BY). The use, distribution or reproduction in other forums is permitted, provided the original author(s) and the copyright owner(s) are credited and that the original publication in this journal is cited, in accordance with accepted academic practice. No use, distribution or reproduction is permitted which does not comply with these terms. 